Tesis. Año 14, 13(17), 2020, 155-170

\title{
Representaciones discursivas de El caso Banchero
}

\author{
Lucina Dionela Dávila Díaz \\ nelitadidavila@gmail.com
}

\section{Resumen}

El objeto de este artículo es mostrar las distintas representaciones discursivas de $E l$ caso Banchero: histórico, periodístico y ficcional (literatura y cine). Es trascendente el reconocimiento histórico de Luis Banchero Rossi, por ser un hombre de empresa, tenaz y perseverante; un gran ejemplo a seguir. En cuanto al discurso histórico, se observará la valoración del personaje como empresario pesquero dentro de la historia y su importancia para el Perú. El discurso periodístico se observa en la investigación del asesinato del personaje y el posterior tratamiento del proceso (debate) por parte de los medios escritos (revistas y periódicos) y la televisión. E1 discurso ficcional se observa a partir de las obras literarias que se basan en la vida y muerte de Luis Banchero, o que, por el contexto pesquero que desarrollan en la trama, se le menciona. También se observa en el análisis de la película Muerte de un magnate, dirigida por Francisco Lombardi y que se proyectó en cines en 1981.

Palabras clave: Representaciones discursivas, Luis Banchero Rossi, debate, crimen, proceso judicial.

\section{Abstract}

The purpose of this article is to show the different discursive representations of The Banchero case: historic, journalistic and fictional (literature and cinema). Luis Banchero Rossi's historic recognition is significant, since he is a businessman, tenacious and persevering, a great example to follow. Concerning the historic speech, the assessment of his personality as a fishing businessman within history and his relevance will be observed for Peru. The journalistic speech is observed in the investigation of the murder of the character and the later treatment of the process (debate) by the written media (magazines and newspapers) and television. The fictional speech is observed from the literary works that are based on Luis Banchero's life and death or that, by the fishing context that is developed in the plot, where he is mentioned. This is also observed in the analysis of the film $A$ business tycoon's death, directed by Francisco Lombardi and projected at the movie theaters in 1981.

Key words: Discursive representations, Luis Banchero Rossi, debate, crime, lawsuit. 


\section{Representaciones discursivas de El caso Banchero}

\section{El caso Banchero en el discurso histórico}

En el contexto histórico, Luis Banchero Rossi fue un ícono de la industria moderna del Perú, reconocido en la historia por su gran aporte en el desarrollo de la pesquería y, por su gran hazaña empresarial, fue reconocido también a nivel internacional. Sin duda, quienes lo conocieron coinciden en la descripción de sus cualidades. Esto lo podemos apreciar en su reconocimiento póstumo en el ámbito pesquero, del cual fue un símbolo de tenacidad y emprendimiento; desde sus inicios como vendedor, su incursión en la pesca y en el periodismo, así como en otros rubros; además, porque supo sortear múltiples adversidades, para luego consolidarse como el empresario pesquero más importante de la época.

En el Libro de oro de la pesquería peruana, publicado en honor a los 50 años de creación de la Sociedad Nacional de Pesquería del Perú — de la cual se dice que Banchero fue fundador-, se considera que las cualidades que lo caracterizaban eran la de creador y hacedor, pues creó una industria casi de la nada. Era un hombre apasionado por aprender, por hacer, y conquistó mercados que jamás nadie hubiera imaginado alcanzar. Banchero hizo que esta industria sea competitiva a nivel mundial, lo que asombró a sus competidores en diferentes partes del mundo. Se considera a Luis Banchero Rossi como un "verdadero Proteo que hizo despertar la riqueza olvidada del mar [...]” (Sociedad Nacional de Pesquería, 2003, p. 35).

El camino que tuvo que recorrer Luis Banchero antes de convertirse en ícono de emprendimiento empresarial comienza en Trujillo. Demostró sus habilidades como vendedor con el negocio del jabón, ya que vio la oportunidad de venderlo en las bodegas de los chinos en la ciudad. Se dice que la venta de alcohol fue también parte de su entrenamiento empresarial. Más adelante formó la empresa Productos y Forrajes, en sociedad con Alicia (prima de Banchero) y luego ocupó el cargo de director gerente de Lubricantes Kendall. Las ventas de este último lo llevarían a conocer Coishco, la más importante envasadora de pescado en conserva de Chimbote. Será ahí donde nace la idea de incursionar 
en este negocio; pero no como dependiente, sino como gestor de su propio sello e inventor de su propia empresa. Junto a un socio, nace Florida, una envasadora de bonito, que empezó a producir en 1955. Posteriormente, se asoció a la empresa Wilbur-Ellis en una pequeña planta de harina de pescado, a la que llamaron Pesquera Humbolt. A los pocos años, compró todas las acciones de la empresa y así empieza su gran trayectoria empresarial e industrial pesquera (Arévalo Alvarado-Zañartu, 1995, pp. 87-88).

Según Arévalo Alvarado-Zañartu (1995), el nombre de Luis Banchero comenzó a sonar nacional e internacionalmente en la década de los sesenta. En vista de la multiplicación de sus empresas (no solo en la pesquería), incursionó en la prensa y en 1963 dio inicio a la cadena de periódicos Correo y Ojo. Simultáneamente, reanudó el envasado de alimentos y creó la empresa envasadora San Fernando, que enlataba vegetales, frutas, carnes y bonito. Así, Banchero puso sus intereses pesqueros bajo el control de Operaciones y Servicios S.A. (OYSSA).

En 1971, controlaba la producción de harina y aceite de pescado, pesca para consumo humano, astilleros, metalurgia, seguros, publicidad, periodismo, transporte marítimo y minería (Arévalo Alvarado-Zañartu, 1995, pp. 87-88). La incursión en la prensa, según Apaza (2015), se debió a que la naturaleza del trabajo de Banchero lo llevó a conocer diversas ciudades y países más modernos, por lo cual notó que era necesario que cuente con un medio que lo ponga al día de todo el acontecer mundial, regional y que eduque a la población. Además, el negocio de la prensa escrita le generó más notoriedad y, sin duda, poder político (Apaza, párrs. 1-7).

Aunque la empresa de mayor envergadura, que logró llevar al Perú a competir con otras empresas que manejaban el mercado mundial, es sin duda la industria de harina de pescado. Banchero, junto a destacados empresarios, dieron su mayor esfuerzo para mejorar la industria pesquera desde 1939. Sin embargo, "la gran revolución pesquera" se produjo en la década de los sesenta, cuando se produjo una profunda transformación que puso las bases para el extraordinario desarrollo de esta industria (Trillo y Tord, 2003, pp. 101-102).

Todo ello se dio gracias al desarrollo de la tecnología y a dos factores adicionales que explican la extraordinaria rapidez con la que creció la industria de harina de pescado en el Perú. El primer factor fue la disponibilidad de bienes de capital de segunda mano y de buena calidad, muy baratos, que hubo durante los años cincuenta y que ayudaron a que la primera inversión de Banchero sea razonablemente rentable para sus inicios como empresario. El segundo factor fue la apertura de la banca comercial peruana para financiar nuevas empresas de harina de pescado (Thorp y Bertram, 1988, pp. 373-377).

Trillo y Tord (2003) destacan que toda esta hazaña de Luis Banchero y otros empresarios pesqueros fomentó una enorme cantidad de negocios colaterales, como la metalmecánica, aplicada a la fabricación de maquinaria especializada, así como otras industrias afines, como la producción de redes, sacos de 
papel, yute y polipropileno, etiquetas, etc. A ello hay que sumar la construcción de astilleros, a través de Pesquería Industrial Callao S.A. (PICSA), que convirtieron al Perú en el mayor y mejor constructor de lanchas de pesca de la costa sur y norte del océano Pacífico. Además, Trillo y Tord precisan que este logro no solo fue para Banchero, sino también para el Perú, ya que para la época fue "los mayores timbres de orgullo de la nación" (2003, p. 106).

Thorp y Bertram (1988), por su parte, afirman que Banchero tuvo desafíos enormes que superar, tanto por parte del gobierno de turno, los problemas sociales, el cambio repentino de los mercados internacionales, hasta la misma naturaleza. Por ejemplo, los altos impuestos establecidos a finales de 1962, lo que trajo como resultado un paro y una huelga que duró un mes; además, la producción peruana de harina de pescado comenzó a hacer peligrar la población de peces y las consecuencias se reflejaron luego durante ese año (Thorp y Bertram, 1988, pp. 336-378).

Córdova (2008) coincide en que Banchero y el resto de pioneros pesqueros debieron aprender, en sus primeros años de auge, una primera y dolorosa lección: no solo bastaría con batir récords de producción, sino que también había que aprender a comercializar la harina de pescado. Para contrarrestar a los especuladores, en el seno de la Asociación Internacional de Productores de Harina de Pescado, impulsaron la formación de una institución denominada Fish Meal Export Organization (FEO), para intercambiar información sobre datos de la producción de los países exportadores y stocks en los importadores. Asimismo, se conformó una suerte de cooperativa de ventas llamada Consorcio Pesquero, que llegó a ocupar el 92\% de la producción local de harina de pescado. El objetivo de este órgano era comercializar unificadamente el producto peruano en todos los mercados y hacer cumplir un recién instaurado sistema de cuotas de exportación a nivel de producción. Al cabo de un tiempo, se venció el obstáculo de los especuladores. Estas son las acciones inmediatas que se impulsaron con el fin de consolidarse en el mercado internacional.

Banchero tuvo que enfrentar otro obstáculo: el de la naturaleza. Más allá de los accidentes de ruta (como el hundimiento de algunas naves), el principal escollo natural que la industria pesquera tardó en aprender a controlar fue el manejo ecológico del recurso y prever la eventualidad del Fenómeno de El Niño. Los fenómenos naturales que afectaron a Luis Banchero se produjeron en 1925, 1941, 1953 y 1957. Nadie esperaba en 1965, cuando la industria estaba en pleno auge de expansión, que se sufriera una auténtica catástrofe para las empresas pesqueras, las cuales en su mayoría habían crecido sobre la base del endeudamiento. El otro obstáculo, probablemente aquel que más daño le hizo al crecimiento del grupo Banchero, fue el de las trabas burocráticas y la angurria tributaria del Estado. La industria casi no nace por la oposición de la 
Compañía Administradora de Guano. Luego vino la creación de un sinnúmero de trámites y permisos para poder operar (Córdova, 2008, pp. 293-295).

\section{El caso Banchero en el discurso periodístico}

Del industrial Luis Banchero Rossi se empezó a hablar de manera pública aproximadamente desde 1960. La revista Pesca proyectó por primera vez su imagen pública en ese año y expresó algunas de sus cualidades: un hombre con visión y con gran capacidad de trabajo, que con treinta años llegó a convertirse en un industrial de talla mundial (Basombrío, 1972, p. 11). Pero no será sino hasta ese fatídico 1 de enero de 1972 en que su nombre y "el caso Banchero" empezó a aparecer en las portadas de diarios, radio, televisión, semanarios y revistas nacionales, ya no por incursionar en nuevos negocios, sino por ser víctima de un cruel asesinato en su casa de campo. Este hecho se difundió a través de los medios de comunicación como un caso de interés nacional por más de cinco años debido a su complejidad.

El asesinato de Luis Banchero Rossi fue impactante para el país. La prensa, en un primer momento, se limitó solo a informar y reconocer su labor y colaboración con el país. Belaunde Terry (1972, p. 11) afirmó que, después de ese trágico 1 de enero, Luis Banchero pasó de la realidad a la leyenda. La prensa nacional presentó remembranzas de la vida del ingeniero Banchero, su importancia en la economía actual, sus proyectos realizados y los que tenía planeado realizar; coincidieron en que era una pérdida irreparable y lamentable. Los medios publicaron titulares llamativos y, en algunos casos, presentaron datos inexactos sobre los hechos, incluso sobre la edad del inculpado. La República tituló: "Un escuálido joven de 17 años sería victimario de Banchero. El cuñado y médico hallaron el cadáver" (2 de enero de 1972, p. 1). Los periodistas, en medio de la confusión de lo ocurrido, incurrieron en errores en las primeras publicaciones. Vilca tenía 19 años en ese momento. Posteriormente, los titulares fueron cada vez más enfáticos. Expreso publicó varios artículos, entre ellos: "En orgía de terror, orate mató a Luis Banchero Rossi. Vilca Carranza dice que lo mataron entre tres" (5 de enero de 1972, p. 4), cuya información se publicó luego de las declaraciones de Juan Vilca y Eugenia Sessarego.

E1 6 de enero de 1972 se realizó la reconstrucción parcial, en la que participaron los inculpados Juan Vilca y Eugenia Sessarego, así como el juez Raúl Cubillas, el agente fiscal José Lozán Tataje y la policía. Luego, se nombró un juez $a d-h o c$ exclusivo para la investigación y la responsabilidad recayó sobre el juez José Santos Chichizola. Dada la importancia de Luis Banchero y los testimonios poco creíbles de los implicados, los medios tomaron parte condenatoria en el caso, por lo que defendieron y acusaron a quienes, según su convicción, eran culpables e inocentes. Los flancos de la discusión comprendieron dos puntos. En un extremo, estaban los diarios Extra, Expreso, la revista Oiga y el periodis- 
ta Tealdo, críticos del procedimiento de las primeras investigaciones del juez Cubillas y con un apoyo total al rol del juez José Santos Chichizola. En el otro extremo, estaban la revista Caretas y el periodista Gonzalo Añi Castillo, defensores de las investigaciones del juez Cubillas, los fiscales que lo acompañaron y la versión de autoinculpación de Vilca. Otros diarios, como El Comercio, Correo y La prensa, se caracterizaron por sus discretas publicaciones sobre el caso y se alejaron del debate periodístico.

El primer debate se dio en torno al aspecto físico del agresor (Juan Vilca). Algunos medios no concebían que una persona de metro y medio de estatura y cincuenta kilos de peso pudiera dominar a un hombre audaz como Banchero, acostumbrado a lidiar con gente ruda del mar (Oiga, 1972, 462, pp. 13-14). El "esmirriado físico" ponía en duda su capacidad para reducir a personas con mayor contextura (El Comercio, 6 de enero de 1972, p. 29). Además, el cuchillo con el que le habría provocado las heridas por la espalda tenía la punta mellada y requeriría de gran fuerza, pero Vilca era de contextura "endeble" (La Prensa, 3 de enero de 1972, pp. 1-6). Este hecho tampoco convence al nuevo juez adhoc José Santos Chichizola quien, desde que se hizo cargo del caso, empezó a analizar otras posibilidades.

La pistola fue un elemento clave y difícil de resolver: primero, por la forma como la obtuvo Vilca, lo que nunca estuvo claro; y segundo, porque se determinó que no pudo usarla el día del crimen. Alfonso Tealdo propone en un programa la teoría del "caballete levantado": el dueño de la pistola tenía que ver que estaba mal cargada, lo que tuvo que notar Banchero de todos modos; además, por la forma como Vilca la esgrimía, no podía hacer disparo alguno, de tal modo que sería un hecho que bastaría para demostrar la falsedad de la tesis del doctor Melgar de que los amenazó con la pistola (Oiga, 1972, 499, p. 13). Vilca había declarado que no mató a Banchero a tiros, porque la pistola Luger se atascó. Caretas explica que podría darse el caso que, cuando los encañonó, no estuvo con el caballete levantado o puede ser que: "[...] Vilca acciona frenéticamente el cargador, pero nunca llega a jalarlo hasta el fondo. La recámara, traban la pistola y luego saltan al suelo, hasta que se termina la cacerina [...]" (1972, 468, p. 16). Caretas criticaba duramente a Tealdo y a Oiga.

Guillermo Thorndike cita, en el capítulo 38 de El caso Banchero, al programa de Alfonso Tealdo que tuvo como invitado al doctor Enrique Melgar. Se puede deducir que Thorndike comparte la tesis del "caballete levantado" expuesta por el periodista (1973, p. 452).

Otro tema en debate fue el de las ataduras en el cuerpo de Banchero y si dejaron huellas o no. Vilca indicó que él los obligó a tirarse al piso y luego obligó a Eugenia Sessarego a que ate a Banchero de pies y manos; pero, de acuerdo a las investigaciones, hubo muchas contradicciones entre lo que dijo Vilca, los que vieron el cadáver y los médicos que analizaron y fotografiaron el cuerpo. 
Informaron que, en el examen que le hicieron a Banchero en la morgue, no se encontró las huellas de las ligaduras que debieron marcar las muñecas y tobillos de la víctima. Así, surgen las interrogantes: “¿O es que la versión que fue atado es falsa? ¿O fue atado después de muerto?” (El Comercio, 4 de enero de 1972, p. 5). Por otro lado, el diario Extra informó: "Dudas, muchas dudas" y luego, en el desarrollo de la noticia, informa: "Sensacional revelación de forenses. ¡Ataron a Banchero después de matarlo!” (4 de enero de 1972, p. 3).

En el semanario Oiga, se explica que, para que algunos vieran las huellas y otros no, es porque:

Según los expertos en medicina legal, las lesiones post-mortem tienen esta característica: solo durante breve tiempo luego desaparecen. En el caso Banchero, si hubo huellas, estas fueron post-mortem. O simplemente no las hubo [...] La respuesta es simple: porque si no han existido esas huellas — como todo parece indicarlo — se destruye la versión inicial del crimen proporcionado tanto de Vilca como por Eugenia, se justificaría la actuación de terceros. (Oiga, 1972, 497, pp. 37)

En Caretas, sin embargo, se explicó la tesis de por qué no hay ataduras. Se indicó que Banchero se mantuvo tranquilo y relajado, le habló amablemente al muchacho, le daba la razón en todo y lo trató de calmar, incluso hablaron de fútbol. La idea es que los soltara o se cansara y se fuera. Además, consideran que las amarras de Banchero se hicieron sobre el pantalón y las medias, así como sobre las mangas de la camisa, a diferencia de Eugenia que estaba con los brazos y tobillos desnudos. Por otro lado, indican que el golpe que recibió Banchero fue sorpresivo y pudo haberlo dejado sin sentido. En otras palabras, Banchero no tuvo tiempo de sentirse herido y forcejear (Caretas, 1972, 451, pp. 5-6).

En cuanto a los golpes que recibió en la cabeza y los cortes del cuchillo que provocaron la muerte de Banchero, para algunos era cuestionable e increíble que Vilca pueda matar con tanto ensañamiento. Con las dudas, surgieron nuevamente otras hipótesis; entre ellas, la participación de terceros en el crimen.

En el número 452 de Caretas, se informó y criticó las nuevas teorías que Alfonso Tealdo y Ricardo Solís sostuvieron sobre los golpes y las heridas que presentaba la víctima. Tealdo indicó que Banchero no pudo ser golpeado con la piedra de 9,5 kilos, sino que debió recibir de pie los golpes de puño y palo, además que no pudo ser Vilca el autor de las puñaladas. En respuesta, sostiene que es falso que la piedra necesariamente tuviera que triturar el cráneo de Banchero y, como dice Enrique Melgar, el cráneo no es cáscara de coco. Se afirmaba que Solís había hecho un verdadero papelón científico en este punto. Finalmente, se subrayó que esos elementos (como el palo) no se encontraron en el escenario del crimen (1972, 452, p. 15). 
A1 respecto, se publicó en Expreso el artículo "Familia Banchero: Juan Vilca no ha actuado solo" (8 de enero de 1972, p. 9). En Oiga, por su parte, se precisa que, si no hay huellas, la versión de Vilca y Eugenia quedarían destruidas, con lo que se justificaría la participación de terceros y se explicaría las lesiones en el rostro de la víctima, producidas ya no por la base de la estatuilla, sino por acción directa de estos terceros desconocidos. Aquellas son lesiones y heridas producidas por elementos contundentes que podrían haber sido una cachiporra, una manopla o un botellazo; la base, por su peso, hubiera causado mayores traumatismos en la víctima (Oiga, 1972, 497, p. 37).

Se debatió también sobre los momentos y oportunidades que Banchero tuvo para salvar su vida. Según las declaraciones de Vilca, se ausentó en cuatro oportunidades, en las que dejó solas a sus víctimas. El abogado Freyre cuestionó esta parte de la reconstrucción y señaló que, cuando Vilca fue al bar y dejó a Banchero sin vendas y con la mano derecha libre, fue una de las oportunidades en las que este pudo hacer algo. Sin embargo, un allegado diría a Caretas que Banchero nunca hubiera dejado a Eugenia sola para encerrarse solo al otro lado de la puerta. Además, explicaron que había que considerar la indeterminada cantidad de alcohol que Banchero ingirió. Melgar ofreció una explicación al hecho: Vilca, hasta ese instante, había aceptado el papel firmado por Banchero y era momento de jugarse el todo por el todo (Caretas, 1972, 450, pp. 12-13).

Otro aspecto que consideraron poco creíble fue por qué Eugenia se dejó; es decir, hizo lo que Vilca le ordenó sin objeción. En Caretas, explicaron que: "Cuando Vilca la lleva finalmente a la cama, ha pasado el momento de pánico más intenso. Eugenia tiene un arma para negociar que es más poderosa que el dinero y las facilidades que Banchero ofrecía a Vilca, y las utiliza” (1972, 451, p. 6). Sin embargo, el peritaje practicado a Juan Vilca demostró que era "afeminado y padece de infantilismo sexual”. Este informe indicó que tenía marcada tendencia al homosexualismo (afirmación que hicieron los peritos psiquiátricos) y que fue entregado al juez Santos Chichizola. Dicho informe puso en duda las afirmaciones de Eugenia Sessarego quien, en su versión, afirmó que fue víctima de violación por parte de Vilca (Expreso, 7 de junio de 1972).

Otro punto del debate fue cuando Eugenia pidió auxilio. El cuestionamiento surgió a raíz de la decisión de llamar a la familia de Banchero y no a la policía. Eugenia argumentó que primero pensó en una tragedia familiar; además, no sabía el teléfono de la policía y no tenía tiempo para buscarlo. Llamó a un número que tenía en mente: el de Enrique Agois, cuñado de Banchero (Caretas, 1972, 451, p. 6). Para otros, Eugenia, al llamar a Enrique Agois indicando que habrían sufrido "un accidente", la colocó en una delicada situación. El cuestionamiento se direcciona al por qué no lo auxilió, por qué no lo libró de las ataduras o por qué no lo puso en una posición más cómoda (Oiga, 1972, 461, p. 14). Además, se cuestionó a Eugenia por no decir la verdad de la 
magnitud del hecho a la familia cuando llamó por teléfono, tampoco les contó de los golpes con la piedra en la cabeza de Banchero ni de las puñaladas; ella minimizó los hechos y calculó que no se propicie un escándalo (Extra, 5 de febrero de 1972, p. 11).

Los medios especulaban y proponían diversas teorías sobre el asesinato que Caretas (1972) trata de desestimar. Estas surgieron en gran parte por las diversas versiones de Juan Vilca y por la importancia de la víctima. Estas teorías las publicó Caretas en su número 451 con el fin de demostrar que no tenían ningún tipo de análisis ni sustento y mostró una confrontación directa con los medios escritos Extra y Expreso al tildarlos de "prensa amarilla del gobierno" (1972, 451, p. 6). Estas teorías sobre el asesinato involucraron al gobierno, un desfalcador, a John Hall (amigo de Eugenia), al marido de Eugenia Sessarego, a Altamann (se trata de Klaus Barbie, un exnazi buscado por la justicia de Lyon y que vivía en Chaclacayo con el nombre de Klaus Altamann), a una mafia misteriosa y afirmaban que estaban torturándolo, que Eugenia lo mató en la cama, que Eugenia lo planeó todo y lo mató con ayuda de Vilca (1972, 451, pp. 6-7).

Entre todas estas teorías, cobró importancia la tesis de que lo estaban torturando. No había huellas de tortura, ni de ataduras, como puntualizó Caretas (1972, 451, p. 6). Por su parte, el semanario Oiga, en su número 462, realizó un resumen de lo que fue el programa Pulso, conducido por Alfonso Tealdo, en donde el médico forense Ricardo Solís Cabrera demostró la verdad del aforismo "los cadáveres hablan". La tesis se resume en ocho puntos y en uno se argumenta la tesis de que fue torturado: "Antes de asestarle en la espalda las puñaladas mortales él o los asesinos lo abatieron a palazos (o cachiporrazos) y puñetazos y Banchero luchó con él o los atacantes, hasta caer desvanecido por el esfuerzo" (Oiga, 1972b, 462, p. 15). La teoría de que Eugenia lo planeó todo, para Caretas vendría del diario Extra que relata las cosas con estilo más novelesco: "Eugenia sedujo y utilizó a Vilca” (1972a, p. 7); además de otras publicaciones que aparecen en primera plana, como "Eugenia: ¡Astuta y diabólica!" (Extra, 27 de enero de 1972, pp. 2-4). Para Caretas, todo lo mencionado era tan asombrosamente ridículo y penoso que solo pudo salir de una mente enferma o de los muchachos de Extra (1972a, p. 7). Oiga, acerca de que Eugenia planeó todo, puntualizó que no significa que el caso esté esclarecido, sino que se tendría que analizar el papel de Morón y Cerruti que, al mover el cadáver, borraron valiosas pistas y pruebas (Oiga, 1972, 459, p. 13). Al respecto, también informó Expreso: "Vilca declaró al juez: lo matamos entre los dos" (27 de enero de 1972, p. 3). Juan Vilca habría confesado al juez que él y Eugenia asesinaron a Banchero.

A este debate se sumaron los informes presentados por las autoridades, los cuales eran tan distintos que también fueron blanco de controvertidas discusiones. La conclusión del fiscal José Lozán Tataje fue objetada por los medios. La revista Oiga citaba a Expreso: "el fiscal habría señalado como móvil el de 
que Vilca tenía un gran complejo de inferioridad y envidia por la posición de magnate, a quien veía acompañado por hermosas mujeres" (Oiga, 1972, 505, p. 38). Con estas afirmaciones, Oiga cuestionó esta conclusión sindicándola de subjetiva y que derivaba de un supuesto. Expreso, por su parte, informaría: "Dura crítica de la parte civil. Agente Fiscal no ha mostrado interés en el caso Banchero" (24 de agosto de 1972, p. 6). Correo dirá: "Doctor Roy Freyre enjuicia dictamen del agente fiscal" (24 de agosto de 1972, p. 16), por considerarlo incompleto y no tratar aspectos importantes que pudieran ayudar al esclarecimiento del caso. En el caso de Caretas, se pronunció y acusó al diario Expreso al indicar que: "ha seguido imperturbable con la misma cantaleta sensacionalista" y del mismo modo se dirige a Oiga: "se ha sumado al terco mercantilismo de quienes quieren seguir vendiendo papel impreso por unos meses más con titular cómodamente absurdo: 'Sigue enigma'" (1972, 463, p. 13); es decir, Caretas consideró que Expreso y Oiga buscaban obtener un beneficio al no aceptar el resultado de las investigaciones del agente fiscal Lozán Tataje y, en una clara defensa al dictamen del fiscal, Caretas aclara que:

El dictamen del Agente Fiscal [...] confirma, después de una amplísima investigación, [...] la simple y trágica verdad que las mentes más serenas y los elementos más informados sospecharon desde el primer momento. Un hombre solo, Vilca mató a Banchero por resentimiento, para robarle y porque padecía de un desvarío mental (Caretas, 1972, 463, p. 13)

Respecto a la conclusión del fiscal Arturo Pacheco Tejada, Oiga refutó esta conclusión e indicó que el informe no fue lo que el público esperaba o simplemente muy pocos estuvieron de acuerdo con él:

Si creía, fundadamente, que la acusación del fiscal, doctor Arturo Pacheco Tejada, iba a aclarar, por fin, la participación de los dos principales inculpados en el horrendo crimen de Chaclacayo - Juan Vilca Carranza y Eugenia Sessarego de Smith - su informe [...], ha echado por tierra tales expectativas [...] Su opinión de que Vilca es el único culpable no es muy convincente, es compartida por muy pocos... (Oiga, 1972, 505, p. 16)

En el otro flanco está Caretas que, con el titular "El dictamen del fiscal Tealdo", criticó la opinión no solo de Oiga, sino también del periodista Alfonso Tealdo y arremete al afirmar: "allí estaban Oiga y Alfonso Tealdo, [...], haciendo intentos ya descarados de influir sobre los tribunales de justicia, desesperados ahora por evitar que una Corte Superior decida al cabo de un año la libertad de la secretaria de la víctima" (1972, 470, pp. 32-35). Con respecto a Oiga, precisó que: "La opinión del fiscal, aseguró, 'es compartida por muy pocos' - como si supiera cuál es la opinión de muchos” (1972, 470, pp. 32-35). Caretas afirmaba que el periodista Tealdo era apoyado por Oiga y Expreso. 
Se debatió también el resultado de las investigaciones del juez ad-hoc José Santos Chichizola. Al respecto, Correo publicó: "Juez no descarta acción de otras personas en crimen" y amplió la información indicando que el juez: "Sostiene que el crimen fue cometido con alevosía y ensañamiento y que Eugenia es responsable del delito que se instruye, aunque no llega a precisar su exacta participación en los hechos investigados, y que estaría probado que ella miente" (18 de octubre de 1972, p. 18). Además, se aseguraba que el informe del juez era diametralmente opuesto al dictamen del agente fiscal José Lozán Tataje. Oiga (1972) justificó el informe del juez José Santos Chichizola indicando que, desde un comienzo, el "caso Banchero" estuvo rodeado de hechos "raros", refiriéndose a Eugenia Sessarego como una presunta sobreviviente que no pide ayuda a la policía, "por consideración a la familia"; a un médico con 25 años de experiencia que no sabe distinguir entre un hombre agonizante y un cadáver; a exguardia civil que no solo permite el traslado ilegal de un cadáver, sino que en los primeros momentos desorienta a sus excolegas y les oculta la existencia de un testigo tan importante como Eugenia Sessarego; a las huellas de ataduras que aparecen y desaparecen; al escenario convertido en un herradero; a un presunto y enclenque victimario, etc. (Oiga, 1972, 497, pp. 15 y 36-39).

Caretas, bajo el titular "El raro juicio del juez" (1972, 467, pp. 18F-18H), hizo una dura crítica al informe del juez ad-hoc José Santos Chichizola y a quienes respaldaron ese informe. El juez inició una acción judicial en su contra por esta razón. En tal sentido, Caretas hizo su descargo explicando cada punto de vista, pero sin dejar de mencionar que el informe del juez fue alabado extravagantemente por otros medios como Extra, Expreso y Oiga. Explicaban que el juez acusó a Caretas por no tener autoridad para criticar el informe, pero que la denuncia no cuestionaba la autoridad que tienen otros para echarle flores. Caretas se dirige duramente a Extra, Expreso y Oiga al considerar que sus publicaciones confundieron y difamaron, además de acusarlos de intentar influir sobre la opinión pública y torcer la justicia, una violación flagrante de los más elementales principios de la objetividad (1972, 467, pp. 18F-18H).

Con esta singular batalla entre los medios, el caso Banchero llegó a su final después de varios años. Aunque Caretas y Oiga para entonces estaban fuera de circulación, otros medios como El Comercio continuaron informando: "Fue una de las más dilatadas audiencias públicas convocada por el Tribunal Correccional en el Perú" (10 de setiembre de 1975). Varios coincidieron en que este proceso fue el más largo de la historia judicial del Perú y además el más costoso, pues se investigó todas las hipótesis posibles y probables para esclarecer el hecho, desde el asesinato (el 1 de enero de 1972) hasta la sentencia del VI Tribunal Correccional, que se dictó el 9 de setiembre de 1975. El caso Banchero nuevamente logró acaparar los titulares de todos los medios: La Prensa presentó en su portada el titular "E1 Tribunal aplicó diez años a Vilca y seis a Eugenia” (10 de setiembre de 1975); Expreso publicó “10 años para Vilca y seis 
para Eugenia" (10 de setiembre de 1975); Extra presentó en su portada "Para vocal Mansilla Novella: ¡Eugenia inocente!” (10 de setiembre de 1975); entre otros datos sobre el resultado de la sentencia.

La revista Gente, en su publicación número 232, presentó un artículo titulado "Un fallo con gruesas fallas". Este medio no solo coincidió en que fue el proceso más largo de la historia judicial peruana, sino: "El proceso judicial más largo de la historia del mundo" (Cortez, 1975, p. 16). Indicó que fue sorpresivo el cargo que se le imputaba a Eugenia — “Comisión por omisión”-, el cual era novedoso y, además, demasiado subjetivo, por lo que el Tribunal debía juzgar sobre la base de pruebas. Entonces, la condena de Eugenia no tenía justificación y no se pudo probar la participación de terceros.

Ya por el año 1976, Gonzalo Añi Castillo, en su columna "Caso Banchero: hora cero", indicó que no hubo un trato igualitario en los medios de comunicación. A Eugenia no se le dio la oportunidad de defenderse; al contrario, se usó los medios para insultarla aún sin saber si era culpable. Indicó que siguió durante dos años el proceso asistiendo a todas las audiencias y por ello publicó el libro El caso Banchero: informe general (Añi Castillo, 1976, p. 12).

\section{El caso Banchero en el discurso ficcional}

\subsection{En la literatura}

La vida meteórica de Luis Banchero Rossi, su éxito como empresario pesquero y la partida inexplicable tras ser víctima de un atroz asesinato, motivó a varios escritores a crear grandes obras, algunas basadas en el crimen y otras que, por la importancia del personaje y el contexto pesquero que narran, es mencionado dentro de la trama.

Por ello, encontramos El caso Banchero (1973) de Guillermo Thorndike, publicada un año después de la muerte del magnate. En el mismo año, Gonzalo Añi Castillo publicó El caso Banchero: informe general, basada también en el crimen del personaje. Posteriormente, Ludovico Cáceres publica Los asesinos de Banchero (2018), donde brinda una versión distinta del asesinato. En la obra Hombres de mar (2011) de Oscar Colchado, aparece con el nombre de Bianchi Ross y, aunque no es el personaje principal, se le menciona en el contexto pesquero.

Pero Luis Banchero no era ajeno al discurso literario mucho antes de ser asesinado. En la obra El zorro de arriba y el zorro de abajo (1971) de José María Arguedas, aparece con el nombre de Braschi que, por las características que se precisan en el libro, podemos deducir que se trata de Luis Banchero. En la obra de Arguedas, Braschi no es un personaje tan admirado por sus hazañas, como en la de Thorndike; sino más bien respetado o temido por las maniobras 
utilizadas para sacarle provecho a cada situación negativa, como en el caso de las huelgas, donde siempre salía ganando.

En la mencionada obra de Colchado, Bianchi Ross es un personaje degradado: aparece como un traficante de drogas, que comercializa a través de sus productos enlatados. Esta información sale de la voz de otro de sus personajes, apodado el Muki, quien afirma ser testigo ocular del hecho, según la obra.

Podemos deducir que los personajes Bianchi Ross de Colchado y Braschi de Arguedas son Luis Banchero Rossi a partir de los diálogos de otros personajes. A Bianchi Ross se le puede identificar por las características descritas por el personaje Melquiades Quinllay (Muki), quien cuenta que trabajó como tripulante de una lancha de Bianchi cuando fue el terremoto de 1970. Los pescadores dentro de la obra lo conocen como el hombre que industrializó la pesca en Chimbote, descendiente de italianos, dueño de PICSA Astilleros y pesquera Humboldt, que su muerte aún no está esclarecida, etc. Con estas características, se puede determinar que se trata del mismo personaje. De igual forma, en la obra de Arguedas, se deduce que Braschi es Luis Banchero Rossi por algunos datos específicos: Braschi puso en circulación un gran diario en Lima, es el más grande industrial en Chimbote y vende harina de pescado a cien países del mundo. Estos son datos que se puede corroborar en la historia de la vida de Banchero Rossi.

Por su parte, la obra de Gonzalo Añi Castillo presenta datos basados estrictamente en la declaración de los involucrados en el crimen, de las personas que fueron llamadas a declarar por su cercanía a la víctima. Se puede observar, además, que Añi le da tratamiento narrativo cercano al estilo de una novela, pero se puede afirmar que el contenido es estrictamente periodístico.

Estas obras analizadas muestran un común denominador: la denuncia. En la obra de Arguedas, publicada antes de la muerte de Banchero, se observa la denuncia por el maltrato a la gente de la sierra por parte de los industriales y armadores que involucran a Braschi, al crecimiento desmedido de Chimbote en un completo desorden y a la proliferación de ambientes de perdición; la denuncia por crear en la población una falsa expectativa de vida, utilizarlos para trabajar arduamente para luego ser despojados de su dinero a través de las prostitutas y las borracheras, por mafias bien organizadas.

En la obra de Thorndike, se puede deducir que la denuncia está dirigida a las autoridades judiciales. Deja claro que será un crimen sin resolver con grandes deficiencias en las primeras investigaciones y que el juez Chichizola nunca podrá comprobar lo que realmente sucedió.

Oscar Colchado denuncia también en su obra el proceder de las autoridades, no solo en la época de Banchero, sino luego durante la década de los noventa, con la comercialización de droga en el puerto de Chimbote, que involucra 
a agentes de los gobiernos de turno. Ludovico Cáceres también muestra el mal proceder del gobierno de Velasco y lo sindica en su obra como autor intelectual del asesinato de Banchero, así como a las autoridades judiciales que omitieron el papel de Klaus Barbie en el caso. Añi Castillo no sale mucho del contexto de la información, pero muestra al final de la obra su total rechazo a la condena que recibió Eugenia Sessarego: "Injusticia contra una testigo convertida en co-autora de asesinato; confusión de no admitirse que cualquier hombre puede morir de cualquier manera" (Añi Castillo, 1973, p. 330).

\subsection{En el cine}

Francisco Lombardi es el cineasta peruano que se interesó por proyectar en la pantalla grande la recreación de la muerte de Luis Banchero Rossi. La película Muerte de un magnate (1981) muestra una trama muy sencilla y se relaciona con la obra de Guillermo Thorndike; es decir, coincide con lo expuesto en el capítulo 31 y lo dicho y sucedido en la primera reconstrucción del seis de enero de 1972. En cuanto a los escenarios, se centra en algunos acontecimientos importantes de Barleto, una entrevista en la televisión, un discurso en El Callao del 21 de diciembre de 1971, una visita a Chimbote y sus últimas actividades de fin de año en 1971 junto a sus empleados (entre ellos, su secretaria Isabel). Es decir, la historia muestra pasajes de las 200 horas antes de la muerte de Banchero que aparecen en la obra El caso Banchero, con la diferencia que en la película se observa un seguimiento paralelo y más enfocado en las actividades de Barleto junto a su secretaria y de José tratando de mostrarlo como ensimismado, soñador y que continuamente intenta espiar a Barleto en su casa de campo. La diferencia más destacada entre la película y la obra de Thorndike se encuentra en los nombres de los personajes: Barleto (Banchero), José Valdivia (Juan Vilca) e Isabel (Eugenia), que son los que más destacan.

\section{Conclusión}

Luis Banchero Rossi es considerado por la historia como un pionero de la pesca industrial, un visionario que diversificó su inversión pensando en lo que una nación requería para ser competitiva a nivel internacional y que su aporte para el Perú sirve de ejemplo e inspiración para las nuevas generaciones. Con su muerte, el debate se alejó de los tribunales y se trasladó hacia los medios de comunicación. Hubo un linchamiento periodístico muy poco conocido hasta ese momento.

En las obras contrastadas y analizadas, podemos observar un aspecto común: la denuncia, contra la administración de la justicia, la corrupción de los gobiernos y el maltrato a la gente humilde por los empresarios. 


\section{Referencias bibliográficas}

\section{Con autor (libros, revistas, blogs y periódicos)}

Añi Castillo, G. (1976). Caso Banchero: hora cero. Expreso, 6 de mayo. -. (1973). El caso Banchero: informe general. Lima: Impresores Tecni- Offset.

Apaza, A. (2015). Correo: Conoce la historia a 53 años de su fundación. Correo, 12 de junio. https://diariocorreo.pe/edicion/tacna/correo-conoce-la-historia-a-53anos-de-su-fundacion-594032/

Arévalo Alvarado-Zañartu, A. (1995). Luis Banchero Rossi. En Historia y fundamentos de la pesquería del Perú (pp. 87-88). Lima: Las Hormigas.

Arguedas, J. (1971). El zorro de arriba y el zorro de abajo. Buenos Aires: Losada.

Basombrío, I. (1972). Luis Banchero Rossi: el hombre que hizo. Correo, 3 de enero.

Belaunde, F. (1972). Banquero, Nacionalista. Correo, 25 de enero.

Cáceres, L. (2018). Los asesinos de Banchero (segunda edición). Lima: Killa.

Colchado, O. (2011). Hombres de mar. Lima: Alfaguara.

Córdova, D. (2008). Luis Banchero Rossi. En P. Cateriano (comp.), Veinte peruanos del siglo XX (pp. 285-299). Lima: Universidad de Ciencias Aplicadas.

Cortez, J. (1975). Un fallo con gruesas fallas. Gente, XIX(232), 16-18.

Lombardi, F. (1981). Muerte de un magnate [película]. Lima: Inca Films.

Sociedad Nacional de Pesquería (2003). Luis Banchero Rossi. Varios autores, Libro de oro de la pesquería peruana (p. 35). Lima: Sociedad Nacional de Pesquería.

Thorndike, G. (1973). El caso Banchero (primera edición). Barcelona: Barral.

Thorp, R. y G. Bertram (1988). El auge de la harina de pescado y su final. Perú:18901977. Crecimiento y politicas en una economía abierta (segunda edición). Lima: Mosca Azul.

Trillo, P, (2003). Palabras del editor. Libro de oro de la pesquería peruana (p. 19). Lima: Sociedad Nacional de Pesquería.

Trillo, P y Tord L. (2003). El nacimiento de una industria. Libro de oro de la pesquería peruana (pp. 91-107). Lima: Sociedad Nacional de Pesquería.

\section{Revistas y periódicos}

¿Caso cerrado? Caretas, 1972, 451, pp. 4-7 y 11.

¿El guardián del complot? Caretas, 1972, 470, pp. 32-35.

10 años para Vilca y 6 para Eugenia. Expreso, 10 de setiembre del 1975, portada.

Ahora la pregunta es: ¿solos Vilca y Sessarego? Oiga, 1972, XI(459), p. 13.

El caso Banchero. Algunos interrogantes más. Oiga, 1972, XI(457), pp. 13-14.

Anatomía de un asesinato informe que acusa a magistrados. Oiga, 1972, XI(497), pp. $15,36,37$ y 39 . 
Confirmado: ni Vilca, ni Eugenia solos. ¿Se defendió Banchero? Oiga, 1972, XI(461), p. 14.

Cuando los cadáveres hablan. Oiga, 1972, XI(462), pp. 15-17.

Desarmando la teoría del caballete levantado. La pistola. Caretas, 1972, 468, p. 16.

Doctor Roy Freyre enjuicia dictamen del agente fiscal. Correo, 24 de agosto de 1972, p. 16. Dudas, muchas dudas. ¡Ataron a Banchero después de matarlo! Extra, 4 de enero de 1972, p. 1-3.

Dura crítica de la parte civil. Agente Fiscal no ha mostrado interés en el caso Banchero. Expreso, 24 de agosto de 1972, p. 6.

El asesino de Banchero estaría identificado. La Prensa, 3 de enero de 1972, pp. 1-6.

El caso Banchero está solucionado, dice Director PIP. El Comercio, 3 de enero de 1972, p. 1.

El creador. Caretas, 1972, 450, pp. 11-14.

El juicio del juez. Caretas, 1972, 467, pp. 18G y 18F-18H.

El Tribunal aplicó diez años a Vilca y seis a Eugenia. La Prensa, 10 de setiembre del 1975, portada.

En orgía de terror orate mató a Luis Banchero Rossi. Expreso, 5 de enero de 1972, p. 4. Familia Banchero: Juan no ha actuado solo. Expreso, 8 de enero de 1972, p. 9.

Hay demasiadas contradicciones. Oiga, 1972, XI(499), p. 13.

Increible: ¡De inculpada a testigo de cargo! Oiga, 1972, XI(505), pp. 16-38.

Juez instructor exclusivo piden para caso Banchero. El Comercio, 6 de enero de 1972, p. 29.

Juez no descarta acción de otras personas en crimen. Correo, 18 de octubre de 1972, p. 18

Muchas interrogantes dejan las versiones dadas sobre el caso. El Comercio, 4 de enero de 1972, p. 5.

Las nuevas teorías. Caretas, 1972, 452, p. 15.

Las nueve preguntas contundentes de Roy. La verdad a medias de Eugenia. Extra, 5 de febrero de 1972, p. 11.

Las razones del fiscal. Caretas, 1972, 463, pp. 12-13.

Otras deficiencias. ¿Irresponsable cabio de escenario? Oiga, 1972, XI(497), pp. 36-38.

Para vocal Mancilla Novella: ¡Eugenia inocente! Extra, 10 de setiembre del 1975, portada.

Peritajes demuestran que Vilca es afeminado y padece de infantilismo sexual. Expreso, 7 de junio de 1972, p. ilegible.

Tribunal impuso 10 años de penitenciaría a Juan Vilca y seis a Eugenia Sessarego. El Comercio, 10 de setiembre del 1975, p. ilegible.

Un escuálido joven de 17 años sería victimario de Banchero. La República, 2 de enero de 1972, p. 3.

Vilca declaró al juez: lo matamos entre los dos. Expreso, 27 de enero de 1972, p. 3. 